\title{
Putting sustainability at the core of knowledge management performance evaluation system
}

\author{
Mostafa Nejati ${ }^{1}$, Amirul Shah Bin Md Shahbudin ${ }^{1}$, and Azlan Bin Amran ${ }^{2}$ \\ ${ }^{1}$ School of Management, Universiti Sains Malaysia, Malaysia \\ ${ }^{2}$ Graduate School of Business, Universiti Sains Malaysia, Malaysia
}

\begin{abstract}
With the transformation of managerial views and the increasing focus on knowledge and intellectual capitals as the most important resources to the organizations, the necessity for retaining these resources and monitoring their effectiveness in order to know how they are utilized becomes significant. As for the universities, this requirement is even higher compared to other organizations, due to the fact that almost a complete chain of knowledge management processes and practices exist in the universities, from knowledge creation, planning, creation, development, and acquisition to knowledge updating, sharing, dissemination, utilization, and protection. Therefore, it is crucial to assess the performance of these knowledge management processes. Yet, it is noteworthy to re-look at universities to find out about their position in the community and their responsibilities towards the society at large. Universities do not operate in vacuum; rather their actions and decisions affect the society and the environment. Hence, any program aimed at evaluating the knowledge management performance of universities must also take into consideration their responsibilities toward the society and its sustainable development. This study emphasizes on the importance of putting sustainable development view at the core of any knowledge management performance evaluation effort and proposes a sustainable development-led framework for evaluating knowledge management performance in the university setting.
\end{abstract}

Keywords: Sustainable Development, Sustainability, Knowledge Management, Knowledge Management Performance Evaluation, Knowledge Framework

\section{Introduction}

As one of the most valuable resources to any organization, knowledge has become a determiner for success or failure of firms. Indeed, managing knowledge (as the process is called knowledge management) has become the key in creating competitive advantages for the firms (Connor and Prahalad, 1996; Hall, 1993; Nonaka \& Takeuchi, 1995) and a driver of organizational excellence. Organizations are now, more than ever, aware of the uniqueness of knowledge and intellectual capitals in bringing competitiveness to their firms.

At the present time, organizations are seeking their competitive advantage in the effective and unique use and development of their knowledge so that it creates new areas of core competencies for them. As Choi, Poon, and Davis (2008) point out, knowledge has nowadays become a major source for organizational competitiveness.

Copyright (C) 2010 Mostafa Nejati, Amirul Shah Bin Md Shahbudin, and Azlan Bin Amran. This is an open access article distributed under the Creative Commons Attribution License unported 3.0, which permits unrestricted use, distribution, and reproduction in any medium, provided that original work is properly cited. Contact Author: Mostafa Nejati, e-mail: Email: mostafa.nejati@ gmail.com 
It is now widely recognized that knowledge assets and technological enhancements are essential strategic resource for any organisation to achieve sustainability and competitive advantage (Nejati and Nejati, 2008).

Organizations are now, more than ever, aware of this unique resource; therefore, they are planning to manage it more effectively through various initiatives including knowledge management projects or practices. This way, they can better survive in today's challenging world and can improve their performance. Yet, having knowledge management systems and plans will not guarantee organizational success. It is crucial to monitor the knowledge management practices and evaluate their performance in the organization.

Of course, it is worth noticing that organizations do not operate in the vacuum. Instead, their actions and decisions affect a larger group than their direct customers and shareholders. Organizations should therefore be responsible toward different stakeholders and the society at large and comply with the sustainable development requirements.

The evaluation of Knowledge Management (KM) performance has provides the reference for managing organisational learning and enhancing competitiveness and excellence (Nejati et al., 2009b).

As knowledge is created and disseminated throughout the organisation, it can contribute to the organisation's performance and improve its readiness to face unusual situations, and turn threats into new opportunities. As a source of competitive advantage, knowledge can also enhance organizational performance if it is applied and managed effectively; therefore it is necessary that some indictors and measures are defined to enable managers to control the performance of the applied knowledge and make decisions about knowledge management activities (Carrillo \& Gaimon, 2004; Pfeffer \& Sutton, 1999; Ribiere \& Sitar, 2003) to ensure effectiveness of KM initiatives (Ahn \& Chang, 2004).

While knowledge management field has extensively been studied before, the question of how to measure KM performance is less explored and is becoming more and more important (Huang, Chen, \& Yieh, 2007) as it can lead to strategic organizational learning and better satisfaction of customers' needs (Mitri, 2003), as well as better organizational performance. Organizations are now extensively alert to the importance of knowledge and $\mathrm{KM}$ practices in order to efficiently use their intellectual assets. Universities, as leading organizations in creating, disseminating and applying knowledge within the society, are far more concerned about this, because, retaining an effective and efficient knowledge management process can help them to maintain a sustainable competitive advantage and reach its organizational objectives (Davenport, DeLong, \& Beer, 1998). Although there some studies on KM in the higher learning institutes, the application of KM needs to be further explored (Yahya and Zahrawi, 2009). As a result, the evaluation of knowledge management performance in the universities and higher education institutes is very crucial. Yet, we believe that any initiative that aims to look into the performance of knowledge and intellectual assets in the university-setting should not ignore the responsibilities of the university towards the society. In fact, this has been a drawback of most previous studies on KM, as they have ignored sustainability and failed to take into account the sustainable development commitments of the university in their studies and frameworks.

It is very important to re-consider the social responsibilities of universities and their roles in enhancing the Sustainable Development (SD). There is no doubt that universities play a significant role in the society and universities are considered to be heralds in knowledge management processes which their actions and decisions will affect the society. Therefore, it is necessary to take into account the roles and decisions of universities regarding the 
sustainable development, and focus on them in the studies; something which has been greatly missing in the previous studies.

\section{Sustainable development view by universities}

In December 2002, the United Nations (UN) General Assembly adopted resolution $57 / 254$ and announced the United Nations Decade of Education for Sustainable Development (DESD) from 2005 to 2014 for which UNESCO was designated to lead it (UNESCO, 2010). Ever since, more and more universities worldwide have launched programs and projects in order to include sustainable development view in their curricula and strategies; for example Universiti Sains Malaysia (USM), VU University Amsterdam, University of Hawai'i at Manoa, etc.

Universities are now more aware of their roles in the society and how they should contribute to it. They do not anymore consider their students, professors and staffs as their only members who will be influenced by the university decisions. Rather, they know that the decisions made by the university and the outputs from the university processes will have an impact on the society.

Of course undertaking a sustainable approach will bring about numerous benefits, including brand value and reputation enhancement, increasing innovation, increased revenues and many more (Sigma Guidelines, 2003), while failure to take sustainable development responsibilities can result in a loss of competitive advantage and business opportunities and lower long-term performance (Robinson et al., 2006).

Therefore, universities must focus on sustainable development as a beneficial requirement and put it at the core of their processes.
Sustainable-development-led KMP evaluation framework

Managing knowledge assets in organizations is inevitable in order to maintain the organizational competitiveness. That's why knowledge management has become a major determinant of organizational survival (Chang \& Wang, 2009).

Yet, having knowledge management processes and systems in the organization does not guarantee better organizational performance. It is necessary that the real performance of knowledge management practices are monitored and evaluated.

Recently, many scholars have attempted to measure the contribution of the KM by different methods (Malhotra \& Segars, 2001; Maltz, Shenhar, \& Reilly, 2003; Ngai \& Chan, 2005). Also companies have strived to manage knowledge more effectively in order to improve corporate performance (Choi \& Lee, 2003).

Nejati et al. (2009a) suggested that this KMP evaluation should be done at four different levels, namely: individual, cross-individuals, organizational, and cross-organizational levels. This categorization is suitable for university-setting as well, especially because knowledge is created, shared utilized and retained by and among individuals and organizations.

In another study, Nejati et al. (2009b) have already discussed about the importance of knowledge management performance evaluation in the university-setting and how sustainability can be embedded with it. They have proposed an initial framework for evaluation of knowledge management performance with a sustainable development view. In this paper, we have developed that initial framework and come up with a more comprehensive and detailed sustainable-development-led evaluation framework for knowledge management performance (KMP) in the university setting. This framework has been illustrated in Figure 1 below. 




Figure 1: Sustainable-development-led KMP evaluation framework

The proposed research framework consists of different layers. In the core of the model is the sustainable development role of the university as part and parcel of activities that the university undertakes. This emphasizes on the fact that the responsibilities of university toward sustainable development should be considered and incorporated into every action taken.

The second layer entails the practices and drivers of knowledge management which we call each of them as a step. These include:

KM Planning - KM Planning consists of determining the aims for undertaking knowledge management and organization's expectations from it. Moreover, it entails the planning process for deciding about the types of knowledge that are important to the organization.

Knowledge identification - Once information and knowledge were scarce, but this is not a problem anymore. The real problem is that we are bombarded with loads of information and piles of knowledge. Therefore, it is crucial to distinguish between the useful knowledge and the other ones. This step entails review of existing knowledge to identify available sources of knowledge and decide about the areas in which the organization needs to focus to develop required knowledge. As probst (1998) has pointed out, it is necessary that organizations get to know about the existing knowledge within their organization as well as outside, before they decide to spend huge amounts of money for developing new sources of knowledge - which might already exist.

Knowledge creation/development - Creating new knowledge sources and developing available knowledge is a very crucial component of knowledge management which this step of the model covers it.

Knowledge Acquisition/Updating - Acquiring and capturing of new or existing knowledge in the organization and by the knowledge workers is another important step in the knowledge management practice. Besides, it is important to update the knowledge repositories and sources of knowledge on a regular basis. This step of the model covers these practices. 
Knowledge Sharing/Dissemination - To share and convey the knowledge with others and at different levels and disseminate in formation throughout the organization is another part of a knowledge management process which forms one of the stages of the proposed model.

Knowledge Utilization - The knowledge should be utilized in order to create value added to the knowledge workers and organization. This stage of the model entails utilization of knowledge in work or daily life.

Knowledge Protection - Ensuring to preserve the knowledge assets in the organization and categorizing them according to different access levels is an important part of $\mathrm{KM}$ process which is introduced in this step of the model.

KM Drivers - The success of a knowledge management project depends on several factors (e.g. incentives system, organizational culture, etc.). This step looks into the most important factors which can form the foundation for a successful KM and act as a driver toward its success.

\section{Conclusion}

This paper has studied the importance of sustainable development view for universities, and has emphasized on the necessity for putting sustainability at the core of knowledge management performance evaluation framework. As such, a KMP evaluation framework with the focus on sustainable development has been proposed and each of its layers and components has been analyzed.

The framework can act as an initial tool which based on that, the key performance indicators can be defined and help to assess the performance of knowledge management practices under the umbrella of sustainable development.

Future research can focus on defining the relevant indicators for the proposed framework and applying it in some pilot cases.

\section{Acknowledgement}

Authors would like to acknowledge Universiti Sains Malaysia (USM) for supporting towards the publication of this paper through USM Fellowship.

\section{References}

Ahn, J.H. and Chang, S.G. (2004), "Assessing the contribution of knowledge to business performance: The KP3 methodology", Decision Support Systems, Vol. 36 No. 4, pp. 403-416.

Carrillo, J.E. and Gaimon, C. (2004), "Managing knowledge-based resource capabilities under uncertainty", Management Science, Vol. 50 No. 11, pp. 1504-1518.

Chang, T.H. and Wang, T.C. (2009), "Using the fuzzy multi-criteria decision making approach for measuring the possibility of successful knowledge management", Information Sciences, Vol. 179 No. 4, pp. 355-370.

Choi, B. and Lee, H. (2003), "An empirical investigation of KM styles and their effect on corporate performance", Information \& Management, Vol. 40 No. 5, pp. 403-417.

Choi, B., Poon, S.K. and Davis, J.G. (2008), "Effects of knowledge management strategy on organizational performance: a complementarity theory-based approach", Omega, Vol. 36 No. 2, pp. 235-251.

Connor, K.R. and Prahalad, C.K. (1996), "A resource-based theory of the firm: knowledge versus opportunism", Organization Science, Vol. 7 No. 5, pp. 477501.

Davenport, T.H., Jarvenpaa, S.L. and Beers, M.C. (1996), "Improving knowledge work processes", Sloan Management Review, Vol. 37 No. 4, pp. 53-65.

Hall, R. (1993), "A framework linking intangible resources and capabilities to sustainable competitive advantage", Strategic Management Journal, Vol. 14 No. 8, pp. 607-618. 
Huang, M.J., Chen, M.Y. and Yieh, K. (2007), "Comparing with your main competitor: the single most important task of knowledge management performance measurement", Journal of Information Science, Vol. 33 No. 4, pp. 416-434.

Malhotra, G.A. and Segars, A. (2001), "Knowledge management: an organisational capabilities perspective", Journal of Management Information Systems, Vol. 18 No. 1, pp. 185-214.

Maltz, A.C., Shenhar, A.J. and Reilly, R.R. (2003), "Beyond the balanced scorecard: refining the search for organisational success measures", Long Range Planning, Vol. 36 No. 2, pp. 187-204.

Mitri, M. (2003), "Applying tacit knowledge management techniques for performance assessment", Computers \& Education, Vol. 41 No. 2, pp. 173-89.

Nejati, M. and Nejati, M. (2008), Enabling Knowledge Sharing and Innovation within organizations. Proceedings of the 1st Iranian International Knowledge Management Conference, Tehran, Iran.

Nejati, M., Md Shahbudin, A.S., Amran, A. and Nejati, M. (2009a), "Knowledge Management Performance Award (KMPA) for Universities \& Institutes of Higher Education", in Managing complexities in the Asia Pacific Region proceedings of the 14th Asia Pacific Management Conference, Surabaya, Indonesia.

Nejati, M., Md Shahbudin, A.S. and Amran, A. (2009b). Knowledge Management Performance Evaluation in Universities: A Sustainable Development View. Creating Global Economies through Innovation and Knowledge Management. Proceedings of the $12^{\text {th }}$ International Business Information Management Association Conference, Kuala Lumpur, Malaysia.

Nejati, M., Md Shahbudin, A.S. and Amran, A. (2010), "Sustainable development: a competitive advantage or a threat? Business Strategy Series, Vol. 11 No. 2, pp. 84-89.
Ngai, E.W.T. and Chan, E.W.C. (2005), Evaluation of knowledge management tools using AHP. Expert Systems with Applications, Vol. 29 No. 4, pp. 889-899.

Nonaka, I. and Takeuchi, H. (1995), The knowledge creating company. Oxford: Oxford University Press.

Pfeffer, J. and Sutton, R. (1999), The knowing-doing gap, Boston: Harvard Business School Press.

Probst, G. (1998), Practical Knowledge Management, in: Prism, Arthur D Little, Second Quarter, 17-29, Retrieved March 24, 2010, from http://genevaknowledgeforum.ch/downloa ds/prismartikel.pdf

Ribiere, V.M. and Sitar, A.S. (2003), "Critical role of leadership in nurturing a knowledgesupporting culture", Knowledge Management Research \& Practice, Vol. 1 No. 1, pp. 39-48.

Robinson, H.S., Anumba, C.J., Carrillo, P.M. and Al-Ghassani, A.M. (2006), "STEPS: a knowledge management maturity roadmap for corporate sustainability", Business Process Management Journal, Vol. 12 No. 6, pp. 793-808.

Sigma Guidelines (2003), "Putting sustainable development into practice - a guide for organisations", Sigma Project. Retrieved March 24, 2010 from http://www.projectsigma.co.uk/Guidelines /SigmaGuidelines.pdf

UNESCO (2010). UN Decade of Education for Sustainable Development. Retrieved February 04, 2010 from http://www.unesco.org/en/esd/decade-ofesd/

Yahya, Y. and Zahrawi, A.A. (2009). A Framework for Knowledge Management System in Higher Learning Institution: A Case Study of National University of Malaysia. 2009 International Conference on Electrical Engineering and Informatics, Selangor, Malaysia. 